\title{
Radiation-Induced Change
}

National Cancer Institute

\section{Source}

National Cancer Institute. Radiation-Induced Change. NCI Thesaurus. Code C22493.

Techniques used for altering the genetic material of an organism by exposure to ionizing radiation. 